\title{
Comparison of Clinical Characteristics of Patients With Gastroesophageal Reflux Disease Who Failed Proton Pump Inhibitor Therapy Versus Those Who Fully Responded
}

\author{
Ram Dickman, ${ }^{1 *}$ Mona Boaz, ${ }^{2}$ Shoshanna Aizic, ${ }^{1}$ Zaza Beniashvili, ${ }^{1}$ Ronnie Fass ${ }^{3}$ and Yaron Niv ${ }^{1}$ \\ ${ }^{1}$ Department of Gastroenterology, Rabin Medical Center, Beilinson Hospital, Petach Tikva, Israel; ${ }^{2}$ Epidemiology Unit, Edith Wolfson Medical \\ Center, Holon, Sackler Faculty of Medicine, Tel Aviv University, Israel, ${ }^{3}$ Section of Gastroenterology, Department of Medicine, Southern Arizona \\ VA Health Care System and University of Arizona Health Sciences Center, Tucson, AZ, USA
}

\section{Background/Aims}

Refractory gastroesophageal reflux disease (GERD) is very common, affecting up to $40 \%$ of the patients receiving proton pump inhibitor (PPI) therapy. However, there is not much information about the clinical characteristics of these patients. The aim of the study is to compare the clinical characteristics of PPI responders vs non-responders.

\section{Methods}

Consecutive GERD patients receiving PPI once or twice daily were evaluated by a questionnaire and a personal interview regarding their demographics, habits, clinical characteristics and endoscopic findings. The patients were divided into 3 groups: Patients who fully responded to PPI once daily (Group $A, n=111$ ), patients who failed PPI once daily $(G$ roup $B, n=78$ ) and patients who failed PPI twice daily (Group $C, n=56$ ).

\section{Results}

A total of 245 patients $(59.3 \%$ females, $52 \pm 17.2$ years of age) were included in this study. Cross-group differences (A vs $B$ vs C) were detected for hiatal hernia ( $33 \%$ vs $51 \%$ vs $52 \%, P=0.011)$; erosive esophagitis ( $19 \%$ vs $51 \%$ vs $30 \%, P<$ $0.0001)$; cough $(24 \%$ vs $44 \%$ vs $43 \%, P=0.007)$; sleep disturbances $(19 \%$ vs $30 \%$ vs $38 \%, P=0.033)$; chest symptoms ( $21 \%$ vs $35 \%$ vs $41 \%, P=0.010)$; Helicobacter pylori status $(25 \%$ vs $33 \%$ vs $48 \%, P<0.0001)$, disease duration $(1.6 \pm$ 0.8 vs $1.9 \pm 1.0$ vs $2.0 \pm 1.1$ years, $P=0.007)$, performed lifestyle interventions $(68.5 \%$ vs $46.7 \%$ vs $69.6 \%, P=0.043)$ and compliance ( $84 \%$ vs $55 \%$ vs $46 \%, P<0.0001$ ).

\section{Conclusions}

PPI failure (either once or twice daily) appears to be significantly associated with atypical GERD symptoms, disease duration and severity, $H$. pylori status, obesity, performed lifestyle interventions and compliance as compared with PPI responders.

(J Neurogastroenterol Motil 2011;17:387-394)

Key Words

Compliance; Gastroesophageal reflux; Proton pump inhibitors

Received: June 22, 2011 Revised: July 19, 2011 Accepted: July 28, 2011

(c) This is an Open Access article distributed under the terms of the Creative Commons Attribution Non-Commercial License (http://creativecommons. org/licenses/by-nc/3.0) which permits unrestricted non-commercial use, distribution, and reproduction in any medium, provided the original work is properly cited.

*Correspondence: Ram Dickman, MD

Division of Gastroenterology, Rabin Medical Center, Beilinson Hospital, 100 Jabotinsky Street, Petah Tiqva 49100, Israel Tel: +972-3-937-7236, Fax: +972-3-921-0313, E-mail: dickmanrw@hotmail.com

Financial support: None.

Conflicts of interest: None. 


\section{Introduction}

Gastroesophageal reflux disease (GERD) is a chronic and common medical problem. Population-based studies have demonstrated that $44 \%$ of the US adult population reports GERDrelated symptoms (heartburn and acid regurgitation) at least once a month and $20 \%$ once a week. ${ }^{1-3}$ In addition, GERD has a significant impact on health-care utilization and patients' quality of life. $^{4,5}$

Currently, proton pump inhibitors (PPIs) represent the cornerstone of GERD treatment. PPIs have been shown to have a profound inhibitory effect on gastric acid secretion resulting in high rates of esophageal mucosal healing and rapid control of GERD related symptoms. ${ }^{6-8}$ However, in recent years, reports of PPI failure in GERD patients have accumulated and it is estimated that about $10 \%$ to $40 \%$ of GERD patients remain symptomatic on standard-dose PPI. ${ }^{9-11}$

In the face of PPI failure, physicians often double the PPI dose, assuming that a higher PPI dose will eventually result in symptom resolution. However, this therapeutic strategy frequently results in a less than satisfactory symptomatic response and the majority of patients continues to experience GERD symptoms despite increased doses of PPI. ${ }^{12}$ As a result, research is now focused on exploring the underlying mechanisms that account for PPI failure.

Several mechanisms have been proposed to account for symptom generation in patients who failed to respond to PPI treatment, which include: weekly acidic reflux, duodeno-gastroesophageal reflux, and esophageal hypersensitivity. ${ }^{13}$ In addition, compliance and adherence to treatment are also considered as an important cause of PPI failure, although none of the studies thus far compared compliance rates between PPI failures and PPI responder patients. In this study, we aimed to compare the clinical characteristics of GERD patients who continued to be symptomatic (PPI failure) on once or twice daily PPI with those who were successfully treated with once-daily PPI (PPI success) while on treatment.

\section{Materials and Methods}

\section{Setting and Patients}

Consecutive GERD patients receiving PPI (omeprazole 20 $\mathrm{mg}$, Dexxon, Israel) once or twice daily for at least 3 months were invited to participate in this study. Prior to PPI treatment, patients reported at least 3 episodes of heartburn per week.

All patients were evaluated by a questionnaire and a personal interview regarding their demographics, habits, compliance with treatment (if patients were taking the PPI daily), adherence to treatment (if patients took the PPI before a meal), clinical characteristics and endoscopic findings. All patients were followed by a specifically designed heartburn clinic at the Rabin Medical Center, Israel.

Patients were divided into 3 groups: patients who fully responded to PPI once daily (group A), patients who failed PPI once daily (group B) and patients who failed PPI twice daily (group C).

The PPI success group (group A) included patients with a history of classic symptoms of GERD (heartburn and acid regurgitation) who reported complete symptom resolution on PPI once a day for the last 3 months.

The PPI failure groups were defined as patients who continued to report classic GERD symptoms (heartburn and acid regurgitation) while on PPI once daily (group B) or twice daily (group C), at least 3 times a week for the last 3 months. Patients with atypical or extraesophageal manifestations of GERD were included in this study, as long as they complained of classic symptoms of GERD (heartburn and acid regurgitation) at the same time. Compliance and adherence to treatment were established during a personal interview and later were matched with information from patients' electronic files.

Patients were excluded if they had history of gastric or esophageal surgery, were unable to sign an informed consent or unable to provide the information requested by the protocol. This study was approved by the Human Subjects Committee of the Rabin Medical Center.

\section{Procedure}

Patients meeting inclusion criteria were asked to provide a written informed consent before enrollment into the study. Subsequently, patients filled out a detailed questionnaire about demographics, lifestyle modifications related to GERD, compliance and adherence to treatment. Patients were queried about disease duration, the presence of additional extraesophageal manifestations of GERD and about symptoms suggestive of gastroparesis using the validated Gastroparesis Cardinal Symptom Index (GCSI) questionnaire. A validated process of translation of the GCSI into Hebrew was performed prior to its use in this study. 


\section{Demographic Questionnaire}

All patients completed a questionnaire regarding age, gender, ethnicity, level of education, occupation and marital status. Information about current smoking and alcohol-drinking habits was also collected. Body mass index (BMI) was calculated using the individual's weight and height. Patients were asked about comorbidities and other prescribed medications. All patients were asked about status of Helicobacter pylori, whether the infection was ever diagnosed and if eradication was successful (confirmed by a breath test).

\section{Assessment of Atypical Gastroesophageal Re- flux Disease Symptoms}

Patients were asked if they experienced atypical GERD symptoms, such as chest pain, cough, sleep disturbances, hoarseness, abdominal pain and bloating, difficulty in swallowing and asthma.

\section{Assessment of Lifestyle Modifications, Adher- ence and Compliance}

Patients were asked if they avoid late-night meals, if they corrected a recent weight gain (if a weight gain was identified in the prior 3-month visit) and if they avoided a daily consumption of carbonated beverages.

Compliance was assessed during a personal interview by asking the patients if they kept taking the PPI at the prescribed dose during the last 3 months. Adherence was assessed by asking the patients if they took the PPI on an empty stomach, half an hour before a meal. Patients who took the PPI with or after a meal, and those who did not take PPI once a day (stop taking or take as needed) were considered non-adherent and/or non-compliant, respectively.

\section{Endoscopic Data}

Patients' electronic files were evaluated for upper endoscopic findings in order to document the presence or absence of esophageal mucosal injury and hiatal hernia.

\section{Assessment of Symptoms Suggestive of Gas- troparesis}

All patients were asked to complete and to rate symptoms suggestive of gastroparesis. For this purpose we used a translated and validated version of the GCSI. The GCSI consists of 3 subscales of the patient assessment of upper gastrointestinal symp- tom severity index (PAGI-SYM), selected to measure important symptoms related to gastroparesis, including nausea/vomiting, post-prandial fullness/early satiety and bloating. ${ }^{14}$ The nausea/ vomiting subscale is comprised of 3 items: nausea, retching and vomiting. The post-prandial fullness/early satiety subscale is comprised of four items: stomach fullness, inability to finish a normal-sized meal, feeling excessively full after meals and loss of appetite. The bloating subscale is comprised of 2 items: bloating and stomach or belly visibly larger. Overall the GCSI includes 9 questions and each question is rated by the responder according to its severity from 0 to 5 ( $0=$ no symptoms to $5=$ severe symptoms).The total score of GCSI was categorized as "severe" (GCSI > 27) or "mild" (GCSI $\leq 27)$.

\section{Statistical Methods}

Data analysis was carried out using SPSS 11.0 statistical analysis software (SPSS Inc, Chicago, IL, USA). For continuous variables, such as age and duration of illness, descriptive statistics were calculated and reported as mean $\pm \mathrm{SD}$ as well as median (min-max) as appropriate. Normality of distribution of continuous variables was assessed using the Kolmogorov-Smirnov test (cut off at $P=0.010$ ). Categorical variables such as sex and the presence of co-morbidities were described using frequency distributions and were presented as frequency (\%). Depending on the distribution, continuous variables were compared across groups using one way analysis of variance (ANOVA) or the Kruskal Wallis test. Pair wise, post hoc comparisons for significance across differences were assessed by Bonferroni's test or the Mann-Whitney U. Categorical variables were compared across groups using the chi square test (exact as necessary). Multinomial logistic regression was used to model group membership. Odds ratios were estimated with $95 \%$ confidence intervals. All tests were 2 -sided and considered significant at $P<0.05$.

\section{Results}

\section{Demographics}

A total of 245 subjects were included in this study: $111 \mathrm{pa}-$ tients who fully responded to PPI once daily (group A), 78 patients who failed PPI once daily (group B) and 56 patients who failed PPI twice daily (group C).

Subjects' mean age was $52.3 \pm 17.2$ and $59.3 \%$ of the patients were female, with no significant across group differences. Patients' characteristics are presented by group in Table 1 . No 
Table 1. Subject's Characteristics by Treatment Group

\begin{tabular}{|c|c|c|c|c|}
\hline & Group A $(n=111)$ & Group B $(\mathrm{n}=78)$ & Group C $(\mathrm{n}=56)$ & $P$-value $^{\mathrm{a}}$ \\
\hline Age (yr) & $51.4 \pm 17.4$ & $53.9 \pm 16.03$ & $51.6 \pm 18.5$ & 0.581 \\
\hline Sex (\% females) & 63.1 & 56.4 & 57.1 & 0.620 \\
\hline Area of origin $(\%)$ & & & & 0.731 \\
\hline Israel & 64.0 & 55.1 & 53.6 & \\
\hline Eastern Europe & 13.5 & 15.4 & 16.1 & \\
\hline Western Europe & 5.4 & 7.7 & 3.6 & \\
\hline North Africa & 3.6 & 6.4 & 12.5 & \\
\hline Asia & 12.6 & 14.1 & 12.5 & \\
\hline Other & 0.9 & 1.3 & 1.8 & \\
\hline Weight $(\mathrm{kg})^{\mathrm{b}}$ & $70.8 \pm 14.2$ & $74.05 \pm 14.5$ & $70.9 \pm 13.5$ & 0.271 \\
\hline Height $(\mathrm{cm})^{\mathrm{b}}$ & $166.1 \pm 9.5$ & $165.3 \pm 9.8$ & $163.5 \pm 22.1$ & 0.844 \\
\hline $\mathrm{BMI}\left(\mathrm{kg} / \mathrm{cm}^{2}\right)^{\mathrm{b}}$ & $28.7 \pm 4.5$ & $27.2 \pm 5.1$ & $25.6 \pm 4.1$ & 0.061 \\
\hline Obese (\% with BMI $\left.\geq 30 \mathrm{~kg} / \mathrm{cm}^{2}\right)$ & 12.7 & 32.1 & 12.5 & 0.001 \\
\hline Weight $(\mathrm{kg})^{\mathrm{b}}$ & $70.8 \pm 14.2$ & $74.05 \pm 14.5$ & $70.9 \pm 13.5$ & 0.273 \\
\hline Family status (\%) & & & & 0.533 \\
\hline Single & 21.6 & 16.7 & 25.0 & \\
\hline Married & 64.0 & 64.1 & 55.4 & \\
\hline Divorced & 4.5 & 11.5 & 8.9 & \\
\hline Widowed & 9.9 & 7.7 & 10.7 & \\
\hline Number of children ${ }^{b}$ & $1.99 \pm 1.6$ & $2.4 \pm 1.5$ & $2.4 \pm 1.9$ & 0.081 \\
\hline Present smokers (\%) & 15.3 & 5.1 & 12.5 & 0.070 \\
\hline Non-alcohol drinkers (\%) & 80.2 & 87.7 & 92.7 & 0.080 \\
\hline At least one family member with GERD (\%) & 37.2 & 43.6 & 39.3 & 0.722 \\
\hline Present smokers (\%) & 15.3 & 5.1 & 12.5 & 0.070 \\
\hline
\end{tabular}

Group A, patients who fully responded to proton pump inhibitor (PPI) once daily; Group B, patients who failed PPI once daily; Group C, patients who failed PPI twice daily; BMI, body mass index; GERD, gastroesophageal reflux disease.

${ }^{\mathrm{a}} \mathrm{P}$-value is for across-group comparison (post hoc testing was conducted for significant findings), ${ }^{\mathrm{b}} \mathrm{Mean} \pm \mathrm{SD}$.

difference was detected in BMI across patient groups, and when BMI was categorized to obese (BMI $\geq 30 \mathrm{~kg} / \mathrm{m}^{2}$ ) vs non-obese $\left(\right.$ BMI $\left.<30 \mathrm{~kg} / \mathrm{m}^{2}\right)$, group B had a significantly greater proportion of obese subjects compared to group A $(P=0.001)$ or group $\mathrm{C}(P=0.006)$. However, group $\mathrm{A}$ and $\mathrm{C}$ was not significantly different regarding obesity $(P=0.243)$. Present smoking did not differ across groups $(P=0.070)$, with fewer smokers among group B. Alcohol consumption also did not differ across groups $(P=0.080)$, with a somewhat greater proportion of non-drinkers in group $\mathrm{C}$.

\section{Co-morbidities}

Co-morbidities are presented by group in Table 2. H. pylori infection was significantly less frequently observed in group A than group $\mathrm{C}(P=0.002)$ but not lower than group $\mathrm{B}(P=$ 0.061). The difference between group $\mathrm{B}$ and $\mathrm{C}$ was also not significant $(P=0.061)$. Diabetes differed significantly across groups. A significantly greater proportion of patients from group B compared with group A were diabetic $(P=0.010)$, though no difference was detected between groups $\mathrm{A}$ and $\mathrm{C}(P=0.221)$ and the difference between group $\mathrm{B}$ and $\mathrm{C}$ was not significant $(P$ $=0.070)$. In addition, hypoglycemic agents were prescribed significantly more frequently to patients from group $\mathrm{B}$ than group $\mathrm{A}$ $(P=0.001)$ and marginally more frequently than for group $\mathrm{C}(P$ $=0.090)$. Prescription for these medications was not significantly different between group $\mathrm{A}$ and $\mathrm{C}(P=0.111)$. Hypertension was significantly different across groups, with a significantly smaller proportion of patients from group A having hypertension than subjects in group $\mathrm{B}(P=0.008)$ or $\mathrm{C}(P=$ 0.042), but the two treatment failure groups (B and C) did not differ from one another in terms of this co-morbidity $(P=$ 0.133). Chronic liver disease also differed significantly across groups. A significantly smaller proportion of patients from group A had chronic liver disease than patients from group B $(P=$ 0.009). However, patients in group A were not different from patients in group $\mathrm{C}(P=0.111)$ and patients from group $\mathrm{B}$ was not different from patients in group $\mathrm{C}$ regarding the prevalence of chronic liver disease $(P=0.023)$. Significantly fewer antihyper- 
Table 2. Assessment of Co-morbidities, and Use of Medications by Group

\begin{tabular}{lcccc}
\hline & $\begin{array}{c}\text { Group A } \\
(\mathrm{n}=111)\end{array}$ & $\begin{array}{c}\text { Group B } \\
(\mathrm{n}=78)\end{array}$ & $\begin{array}{c}\text { Group C } \\
(\mathrm{n}=56)\end{array}$ & $P_{\text {-value }}{ }^{\mathrm{a}}$ \\
\hline Co-morbidities (\%) & & & & \\
$\quad$ Hypertension & 17.1 & 33.3 & 28.6 & 0.030 \\
Diabetes mellitus & 9.0 & 21.8 & 12.5 & 0.043 \\
Chronic liver disease & 0.9 & 9.0 & 5.4 & 0.031 \\
Ischemic heart disease & 5.4 & 6.4 & 14.3 & 0.111 \\
Renal disease & 0 & 2.6 & 0 & 0.123 \\
Depression & 6.3 & 7.7 & 3.6 & 0.611 \\
Hypothyroidism & 4.4 & 10.3 & 8.9 & 0.281 \\
Irritable bowel syndrome & 3.6 & 6.4 & 3.6 & 0.610 \\
Inflammatory & 0 & 1.3 & 1.8 & 0.410 \\
$\quad$ bowel disease & & & & \\
Asthma & 8.1 & 7.7 & 14.3 & 0.362 \\
H. pylori infection & 25.2 & 33.3 & 48.2 & 0.002 \\
Medications (\%) & & & & \\
Aspirin & 14.4 & 19.2 & 21.4 & 0.480 \\
Antihypertensives & 15.3 & 25.6 & 17.9 & 0.210 \\
Antihyperglycemics & 0.9 & 12.8 & 5.4 & 0.002 \\
Psychiatric medications & 12.6 & 11.5 & 17.9 & 0.531 \\
\hline
\end{tabular}

Group A, patients who fully responded to proton pump inhibitor (PPI) once daily; Group B, patients who failed PPI once daily; Group C, patients who failed PPI twice daily; H. pylori, Helicobacter pylori.

${ }^{\text {a }} P$-value is for across-group comparison (post hoc testing was conducted for significant findings).

glycemic agents were prescribed to group A than group B ( $P=$ $0.001)$, but no difference was noted between group $\mathrm{A}$ and group $\mathrm{C}(P=0.110)$. The difference between group $\mathrm{B}$ and $\mathrm{C}$ was not significant $(P=0.092)$.

\section{Atypical Gastroesophageal Reflux Disease Sym- ptoms}

Atypical GERD symptoms are presented by group in Table 3. A number of symptoms differed significantly across treatment groups. The proportion of subjects reporting cough differed significantly across treatment groups, and was significantly less frequently reported by patients in group A than those in group B $(P$ $=0.004)$ or $\mathrm{C}(P=0.007)$; however, there was no significant difference between group $\mathrm{B}$ and $\mathrm{C}(P=0.144)$. Sleep disturbances significantly differed across groups, driven by the significantly lower prevalence among group $\mathrm{A}$ than group $\mathrm{C}(P=$ 0.006). The prevalence of sleep disturbances was marginally lower in group A compared with group $\mathrm{B}(P=0.065)$ and marginally lower in group $\mathrm{B}$ compared with group $\mathrm{C}(P=0.090)$. Chest pain was significantly less prevalent in group $\mathrm{A}$ than group $\mathrm{B}(P$ $=0.025)$ or group $\mathrm{C}(P=0.003)$, but there was no significant
Table 3. Assessment of Atypical Gastroesophageal Reflux Disease Symptoms by Group

\begin{tabular}{lcccc}
\hline & $\begin{array}{c}\text { Group A } \\
(\mathrm{n}=111)\end{array}$ & $\begin{array}{c}\text { Group B } \\
(\mathrm{n}=78)\end{array}$ & $\begin{array}{c}\text { Group C } \\
(\mathrm{n}=56)\end{array}$ & $P$-value \\
\hline $\begin{array}{l}\text { Symptoms (\%) } \\
\text { Cough }\end{array}$ & & & & \\
Hoarseness & 24.3 & 43.6 & 42.9 & 0.008 \\
Difficulty in swallowing & 22.5 & 25.6 & 30.4 & 0.540 \\
Sleep disturbances & 18.9 & 30.8 & 35.7 & 0.221 \\
Chest pain & 20.7 & 34.6 & 37.5 & 0.033 \\
Abdominal pain & 31.5 & 39.7 & 51.1 & 0.010 \\
Bloating & 23.4 & 26.9 & 30.4 & 0.065 \\
\end{tabular}

Group A, patients who fully responded to proton pump inhibitor (PPI) once daily; Group B, patients who failed PPI once daily; Group C, patients who failed PPI twice daily.

${ }^{a} P$-value is for across-group comparison (post hoc testing was conducted for significant findings).

Table 4. Endoscopic Findings by Group

\begin{tabular}{lcccc}
\hline & $\begin{array}{c}\text { Group A } \\
(\mathrm{n}=111)\end{array}$ & $\begin{array}{c}\text { Group B } \\
(\mathrm{n}=78)\end{array}$ & $\begin{array}{c}\text { Group C } \\
(\mathrm{n}=56)\end{array}$ & $P$-value \\
\hline $\begin{array}{l}\text { Diaphragmatic hernia (\%) } \\
\text { Erosive Esophagitis (\%) }\end{array}$ & 33.3 & 51.3 & 51.8 & 0.017 \\
$\quad$ & 18 & 51.3 & 30.4 & $<0.0001$ \\
Any grade & 18 & 92.5 & 76.5 & 0.001 \\
Los Angeles Grade A-B & 95 & 7.5 & 23.5 & 0.001 \\
\hline
\end{tabular}

Group A, patients who fully responded to proton pump inhibitor (PPI) once daily; Group B, patients who failed PPI once daily; Group C, patients who failed PPI twice daily.

${ }^{a} P$-value is for across-group comparison (post hoc testing was conducted for significant findings).

difference between group B and C $(P=0.113)$.

\section{Endoscopic Findings}

Endoscopic findings are presented by group in Table 4 . Hiatal hernia was significantly less prevalent in group A than either group $\mathrm{B}(P=0.011)$ or group $\mathrm{C}(P=0.021)$. However, there was no difference in the prevalence of hiatal hernia between group $\mathrm{B}$ and $\mathrm{C}(P=0.550)$. Erosive esophagitis was significantly more prevalent in group $\mathrm{B}$ than either group A $(P<$ $0.0001)$ or $\mathrm{C}(P=0.008)$. Erosive esophagitis was significantly more frequent in group $C$ than group A $(P=0.033)$. Significantly less severe grading of erosive esophagitis (Los Angeles A and $\mathrm{B})$ was noted in group $\mathrm{C}$ than $\mathrm{B}(P=0.011)$ or $\mathrm{A}(P=$ $0.001)$ but no difference between group $\mathrm{A}$ and $\mathrm{B}(P=0.561)$ was noted. Significantly more severe grading of erosive esophagitis (Los Angeles $\mathrm{C}$ and $\mathrm{D})$ was noted in group $\mathrm{C}$ than $\mathrm{B}(P=$ 
$0.010)$ or $\mathrm{A}(P=0.001)$ but no difference between group $\mathrm{A}$ and $\mathrm{B}(P=0.562)$ was noted (Table 4$)$.

\section{Lifestyle Modifications, Adherence and Com- pliance With Treatment}

Patients were asked if they avoid late-night meals, if they corrected a recent weight gain, and if they avoid a daily consumption of carbonated beverages. Significant differences across group were also detected for lifestyle interventions (cross-group differences for $\mathrm{A}$ vs $\mathrm{B}$ vs $\mathrm{C}$ were $68.5 \%$ vs $46.7 \%$ vs $69.6 \%$, respectively $[P=0.042])$, which were significantly less frequently implemented by group B than either group A $(P=0.007)$ or group $\mathrm{C}(P=0.007)$. There was no significant difference in lifestyle modification between group $\mathrm{A}$ and $\mathrm{C}(P=0.511)$.

As previously mentioned, patients who took the PPI with or after a meal and those who did not take the prescribed PPI dose were considered non-adherent and/or non-compliant. Crossgroup differences for group: A vs B vs C were $84 \%$ vs $55 \%$ vs $46 \%$, respectively $(P<0.0001)$. Subjects in group A reported significantly higher adherence and compliance with treatment than subjects in group B $(P<0.0001)$ or $\mathrm{C}(P<0.0001)$. Adherence and compliance were marginally lower in group $\mathrm{C}$ compared to group B $(P=0.084)$.

\section{Symptoms Suggestive of Gastroparesis}

Symptom severity score, as measured by the GCSI, differed significantly across groups and was significantly lower in group A than group $\mathrm{B}(P=0.033)$ or group $\mathrm{C}(P=0.001)$. The total GCSI score (mean $\pm \mathrm{SD}$ ) for group A vs $\mathrm{B}$ vs $\mathrm{C}$ was $11.05 \pm$ 9.22 vs $14.07 \pm 8.50$ vs $16.30 \pm 10.40$, respectively $(P=$ $0.002)$. However, the difference between group $\mathrm{A}$ and group $\mathrm{B}$ was not statistically significant $(P=0.170)$. The prevalence of symptoms that were classified as severe (score $\geq 27$ ) differed significantly across groups. The prevalence of severe GCSI (expressed as percentages) for group: A vs B vs $\mathrm{C}$ was $6.3 \%$ vs $7.7 \%$ vs $19.0 \%$, respectively ( $P=0.023)$. Symptoms that were classified as severe were 2-fold more frequently present in group $\mathrm{C}$ than group A $(P=0.010)$ or group B $(P=0.042)$. However, the prevalence of symptoms that were classified as severe did not differ between group $\mathrm{A}$ and $\mathrm{B}(P=0.223)$.

\section{Multinomial Logistic Regression}

Group membership was modeled using multinomial logistic regression. As can be seen in Table 5, hernia, cough and increased GCSI significantly diminished the odds of being a res-
Table 5. Multinomial Logistic Regression of Group Membership OR $\quad 95 \% \mathrm{CI}$ for OR $\quad P$-value $^{\mathrm{a}}$

\begin{tabular}{lccc}
\hline Group A & & & \\
Intercept & & & 0.12 \\
Hernia & 0.46 & $0.228-0.98$ & 0.045 \\
Cough & 0.36 & $0.16-0.78$ & 0.01 \\
$\quad$ Implementation of lifestyle & 0.79 & $0.35-1.78$ & 0.571 \\
$\quad$ interventions & & & \\
Compliance with treatment & 9.59 & $4.19-21.94$ & $<0.001$ \\
GCSI & 0.94 & $0.91-0.98$ & 0.003 \\
$\quad$ Obese (BMI $\left.\geq 30 \mathrm{~kg} / \mathrm{cm}^{2}\right)$ & 1.18 & $0.40-3.47$ & 0.766 \\
Group B & & & \\
Intercept & & & 0.069 \\
Hernia & 0.97 & $0.45-2.06$ & 0.926 \\
Cough & 0.98 & $0.46-2.10$ & 0.96 \\
Implementation of lifestyle & 0.33 & $0.15-0.72$ & 0.005 \\
$\quad$ interventions & & & \\
$\quad$ Compliance with treatment & 1.69 & $0.79-3.65$ & 0.174 \\
GCSI & 0.97 & $0.94-1.01$ & 0.126 \\
Obese (BMI $\left.\geq 30 \mathrm{~kg} / \mathrm{cm}^{2}\right)$ & 3.82 & $1.45-10.09$ & 0.007 \\
\hline
\end{tabular}

Group A, patients who fully responded to proton pump inhibitor (PPI) once daily; Group B, patients who failed PPI once daily; Group C, patients who failed PPI twice daily; GSCI, Gastroparesis Cardinal Symptom Index; BMI, body mass index.

ORs were estimated with 95\% CIs. All tests are 2-sided and considered significant at $P<0.05 .{ }^{\mathrm{a}} P$-value is for across-group comparison (post hoc testing was conducted for significant findings).

ponder, while compliance with treatment increased the odds of being a responder by more than 9-fold. Furthermore, implementation of lifestyle modifications significantly reduced the odds of single treatment failure, whereas obesity more than tripled the odds of belonging to this group.

\section{Discussion}

The present study provided a comprehensive assessment of the clinical characteristics of GERD patients who responded to PPI therapy compared to those who did not. We noted that non-responders to standard dose PPI (group B) were much different from the responders (group A) in several important clinical characteristics, such as: atypical GERD symptoms, disease duration and severity, obesity, $H$. pylori status and compliance during treatment.

Lack of response to PPI treatment was associated with poorer adherence and/or compliance with treatment. Responders to standard dose PPI (group A) reported significantly higher compliance with treatment than either the single or double treatment failure groups. The finding of poor compliance during PPI treat- 
ment among GERD patients has been previously described in several studies. According to a large population-based survey only $55 \%$ of the GERD patients took their PPIs as prescribed, whereas $37 \%$ failed to follow their therapeutic regimen for more than two weeks. ${ }^{15}$ In GERD, the main obstacle in achieving proper compliance is related to the fact that GERD is a symptom-driven disease in which patients adhere to treatment instructions as long as they experience symptoms. Hungin et $\mathrm{al}^{16}$ found that the presence or absence of symptoms, the severity of symptoms, and personal preference about when to take treatment, played a role in patient's adherence to the schedule of medication consumption. In a systematic review, Fass et $\mathrm{al}^{10}$ reported additional factors that affect compliance and adherence to treatment instructions, such as knowledge about the treated disorder, desire for personal control, the prescribed drug (taste, consistency, etc), side effects, number of pills per day, concomitant therapies, age, personality, socioeconomic status and healthcare coverage.

Timing and frequency of dosing are pivotal for maximum efficacy of medications such as PPIs. The latter should be taken on an empty stomach, 30 minutes prior to a meal. In one study, the authors demonstrated a significantly better gastric $\mathrm{pH}$ control when omeprazole or lansoprazole were taken 15 minutes before breakfast versus without breakfast. ${ }^{17}$ Gunaratnam et $\mathrm{al}^{18}$ found that only half of the patients with persistent GERD symptoms on PPI were dosed optimally and of those who were dosed sub optimally, 39\% consumed their PPI at bedtime and $4 \%$ as needed. In a 2000 Gallup survey, consumption of antireflux medications prior to going to bed was reported by $52 \%$ of the subjects. ${ }^{15}$

In this study, we also found that lifestyle modifications were significantly less frequently implemented by GERD patients who report lack of response to standard dose PPI treatment (group B) than responders to standard dose PPI (group A). Thus, in light of these findings and consistent with findings in other studies, it seems prudent to recommend assessment of compliance and lifestyle modifications, such as weight control and late-night meals, in all GERD patients who report lack of response to PPI treatment. This should be carried out prior to ordering any invasive and costly evaluative tests. Unfortunately, a subset of patients may not disclose that they are poorly compliant during their clinic visit. Treating physicians should repeatedly emphasize the need to consume PPIs on an empty stomach and 30 minutes prior to a meal.

Another important observation of our study was the difference in disease severity across groups as assessed by upper gastrointestinal (GI) endoscopy. We found that non-responders (either to once or twice daily PPI) had more esophageal erosions significantly than responders. There are several explanations for this finding: (1) Hiatal hernia was more prevalent among the non-responders; (2) Non-compliance with treatment was much more frequently observed among non-responders; and (3) The prevalence of obesity (BMI $\geq 30 \mathrm{~kg} / \mathrm{m}^{2}$ ) was higher among non-responders. All the aforementioned, hiatal hernia, obesity and non-compliance may result in higher esophageal acid exposure, and consequently the potential occurrence of esophageal erosions. Another potential explanation is the increase in prevalence of more severe grading of erosive esophagitis (Los Angeles $\mathrm{C}$ and D) among non-responders. This is because grade $\mathrm{C}$ and $\mathrm{D}$ are less responsive to antireflux treatment than grade $\mathrm{A}$ and $\mathrm{B}$.

Interestingly, cough was significantly more prevalent among non-responders than responders. It is possible that non-responders may have a higher degree of proximal esophageal exposure to weekly acidic reflux. A recent impedance-pH study in refractory GERD patients while on PPI therapy showed that up to $68 \%$ of remaining heartburn episodes were associated with weekly acidic reflux. ${ }^{19}$ In this study, high proximal extent of the refluxate was the only important factor associated with perception of reflux events, suggesting an increased sensitivity to chemical stimulus of the proximal esophagus in this group of patients.

We found that past $H$. pylori infection was significantly less frequent in the responders. The explanation for this finding is that the eradication of $H$. pylori infection upregulates gastric acid secretion and consequently increases esophageal acid exposure. Holtmann et $\mathrm{al}^{20}$ demonstrated that of all patients with erosive esophagitis who received 4 weeks of pantoprazole $40 \mathrm{mg}$ daily, $23.7 \%$ of the $H$. pylori-negative patients failed to heal their esophagitis when compared with $13.4 \%$ of the $H$. pylori-positive patients.

Furthermore, in this study, symptoms suggestive of gastroparesis significantly diminished the odds of being a responder. The relationship between refractory GERD and the presence of gastroparesis is an area that has been scarcely studied. A recent study has demonstrated that botulinum toxin injection of the pylorus in gastroparetic GERD patients who failed to respond to PPI treatment significantly improved their symptoms, albeit for a short period of time. ${ }^{21}$

In another study, Kudara et $\mathrm{al}^{22}$ evaluated gastric emptying in 15 patients with erosive esophagitis. Four of the patients who experienced persistent heartburn demonstrated significant delayed gastric emptying when compared with the other 11 patients who had symptomatic improvement. 
An important limitation of the present study is the extraction of endoscopic data from electronic files and not from prospective assessment. Documentation of upper endoscopy results is detailed in our GI department, where all GI physicians use the same computer report system. In our study, compliance was assessed by patient's report rather than by a more objective measure, such as pill count. It is likely that non-compliant patients were inclined to under-report their compliance. If this is the case, then non-compliance with PPI in the treatment failure groups might have been even higher.

In conclusion, our study is the first to provide a comprehensive assessment of the clinical characteristics of GERD patients who failed PPI therapy. We demonstrated that PPI failure (either once or twice daily) appeared to be significantly associated with atypical GERD symptoms, disease duration and severity, $H$. pylori status, obesity, lifestyle modifications and compliance compared with PPI responders. These findings provide an important clinical tool for treating physicians when managing patients with GERD, who are refractory to treatment.

\section{Acknowledgements}

All authors have made substantial contributions to all of the following: (1) the conception and design of the study, or acquisition of data, or analysis and interpretation of data; (2) drafting the article or revising it critically for important intellectual content; and (3) final approval of the version to be submitted.

\section{References}

1. Fass R, Fennerty M, Vakil N. Nonerosive reflux disease - current concepts and dilemmas. Am J Gastroenterol 2001;96:303-314.

2. Locke GR 3rd, Talley NJ, Fett S, Zinsmeister AR, Melton LJ 3rd. Prevalence and clinical spectrum of gastroesophageal reflux: a population based study in Olmsted County, Minnesota. Gastroenterology 1997;112:1448-1456.

3. Nebel OT, Fornes MF, Castell DO. Symptomatic gastroesophageal reflux: incidence and precipitating factors. Am J Dig Dis 1976;21: 953-956.

4. Charbel S, Khandwala F, Vaezi MF. The role of esophageal $\mathrm{pH}$ monitoring in symptomatic patients on PPI therapy. Am J Gastroenterol 2005;100:283-239.

5. Dent J, El-Serag HB, Wallander MA, Johansson S. Epidemiology of gastro-oesophageal reflux disease: a systematic review. Gut 2005; 54:710-717.

6. Dekel R, Morse C, Fass R. The role of proton pump inhibitors in gastrooesophageal reflux disease. Drugs 2004;64:277-295.

7. Coron E, Hatlebakk JG, Galmiche JP. Medical therapy of gastro- esophageal reflux disease. Curr Opin Gastroenterol 2007;23:434439.

8. Chiba N, De Gara CJ, Wilkinson JM, Hunt RH. Speed of healing and symptom relief in grade II to IV gastroesophageal reflux disease: a meta-analysis. Gastroenterology 1997;112:1798-1810.

9. Fass R, Mackel C, Sampliner RE. 24-hour pH monitoring in symptomatic patients without erosive esophagitis who did not respond to antireflux treatment. J Clin Gastroenterol 1994;19:97-99.

10. Fass R, Shapiro M, Dekel R, Sewell J. Systematic review: protonpump inhibitor failure in gastro-oesophageal reflux disease-where next? Aliment Pharmacol Ther 2005;22:79-94.

11. Klinkenberg-Knol EC, Nelis F, Dent J, et al. Long-term omeprazole treatment in resistant gastroesophageal reflux disease: efficacy, safety, and influence on gastric mucosa. Gastroenterology 2000;118:661669.

12. Fass R, Murthy U, Hayden CW, et al. Omeprazole $40 \mathrm{mg}$ once a day is equally effective as lansoprazole $30 \mathrm{mg}$ twice a day in symptom control of patients with gastro-oesophageal reflux disease (GERD) who are resistant to conventional-dose lansoprazole therapy-a prospective, randomized, multi-centre study. Aliment Pharmacol Ther 2000;14:1595-1603.

13. Tack J, Koek G, Demedts I, Sifrim D, Janssens J. Gastroesophageal reflux disease poorly responsive to single-dose proton pump inhibitors in patients without Barrett's esophagus: acid reflux, bile reflux, or both? Am J Gastroenterol 2004;99:981-988.

14. Revicki DA, Rentz AM, Dubois D, et al. Development and validation of a patient assessed gastroparesis symptom severity measure: the Gastroparesis Cardinal Symptom Index. Aliment Pharmacol Ther 2003;18:141-150.

15. The Gallup Organization. The 2000 Gallup study of consumers' use of stomach relief products. Princeton: Gallup Organization 2000.

16. Hungin AP, Rubin G, O'Flanagan $H$. Factors influencing compliance in long-term proton pump inhibitor therapy in general practice. Br J Gen Pract 1999;49:463-464.

17. Hatlebakk JG, Katz PO, Camacho-Lobato L, Castell DO. Proton pump inhibitors: better acid suppression when taken before a meal than without a meal. Aliment Pharmacol Ther 2000;14:1267-1272.

18. Gunaratnam NT, Jessup TP, Inadomi J, Lascewski DP. Sub-optimal proton pump inhibitor dosing is prevalent in patients with poorly controlled gastro-oesophageal reflux disease. Aliment Pharmacol Ther 2006;23:1473-1477.

19. Zerbib F, Duriez A, Roman S, Capdepont M, Mion F. Determinants of gastrooesophageal reflux perception in patients with persistent symptoms despite proton pump inhibitors. Gut 2008;57:156-160.

20. Holtmann G, Cain C, Malfertheiner P. Gastric Helicobacter pylori infection accelerates healing of reflux esophagitis during treatment with the proton pump inhibitor pantoprazole. Gastroenterology 1999;117:11-16.

21. Mirbagheri SA, Sadeghi A, Amouie M, et al. Pyloric injection of botulinum toxin for the treatment of refractory GERD accompanied with gastroparesis: a preliminary report. Dig Dis Sci 2008;53:26212626.

22. Kudara N, Chiba T, Orii S, Suzuki K. Gastric emptying of patients with persistent reflux symptoms and erosive esophagitis under PPI therapy [abstract]. Neurogastroenterol Motil 2004;16:654. 